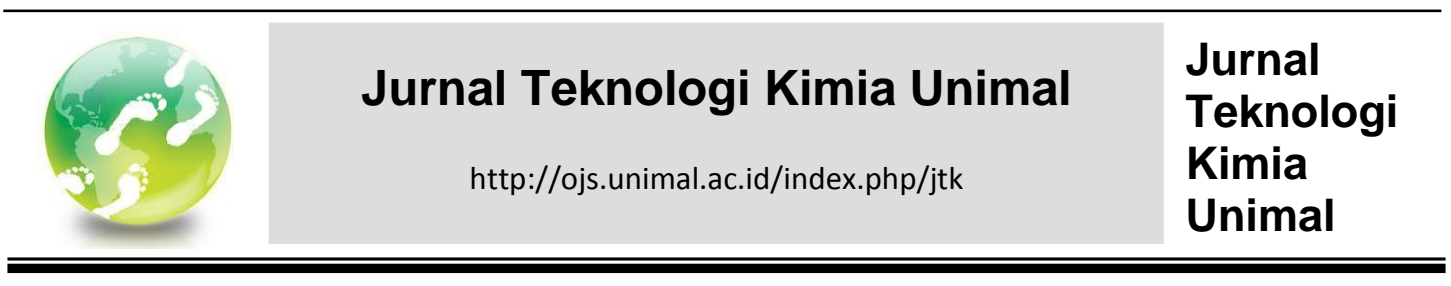

\title{
Optimasi Aplikasi Kontrol PI pada Tekanan di Continuous Stirred Tank Reactor (CSTR) menggunakan Response Surface Methodology (RSM)
}

\author{
Irma Yuliana Damanik, Nasrul Z.A, Muhammad \\ Jurusan teknik kimia universitas malikussaleh \\ e-mail: irma.bulek123@gmail.com
}

\begin{abstract}
Abstrak
Reaktor kimia adalah tempat terjadinya reaksi kimia, baik dalam ukuran kecil seperti tabung reaksi sampai ukuran yang besar seperti reaktor skala industri. Reaktor tangki pengaduk kontinyu (CSTR) adalah bejana dimana reaktan ditambahkan dan produk dikeluarkan sementara isi didalam bejana diaduk dengan kuat dengan agitasi internal atau secara internal (atau eksternal) merecycle isinya. Tujuan dari penelitian ini yaitu untuk menentukan nilai parameter $\mathrm{Kc}$ dan $\mathrm{Ti}$, kontrol yang tepat agar diperoleh respon controller terbaik. Sistem kontrol Proportional Integral and Derivatif (PID) merupakan kontroler mekanisme umpan balik (Feed Back) yang biasanya dipakai pada sistem kontrol industri. Response Surface Methodology (RSM) atau biasa disebut metode permukaan respon adalah sekumpulan metode-metode matematika dan statistika yang digunakan dalam pemodelan dan analisis, yang bertujuan untuk melihat pengaruh beberapa variabel kuantitatif terhadap suatu variabel respon dan untuk mengoptimalkan variabel respon tersebut. Adapun metodologi dari penelitian ini adalah membuat model steady state reactor CSTR menjadi model dynamic, kemudian membuat model kontrol dengan menentukan parameter PI controller menggunakan RSM, setelah itu melakukan tuning parameter kc dan ti terhadap kontrol PI dengan melakukan gangguan pada setpoint. Hasil dari aplikasi sistem kontrol PI maka didapat waktu respon tercepat dengan nilai $\mathrm{kc}=1,85, \mathrm{ti}=1,15$ dengan waktu 0,5 menit.
\end{abstract}

Kata kunci: continuous stirred tank reactor (CSTR), controller PI, set point

\begin{abstract}
Chemical reactors are where chemical reactions occur, both in small sizes such as test tubes to large sizes such as industrial scale reactors. Continuous stirring tank reactors (CSTR) are vessels where the reactants are added and the product is removed while the contents in the vessel are stirred vigorously with internal agitation or internally (or externally) recycle their contents. The purpose of this study is to determine the value of the parameters $\mathrm{Kc}$ and Ti, the right control in order to obtain the best controller response. Proportional Integral and Derivative (PID) control system is a feedback mechanism controller (Feed Back) which is
\end{abstract}


usually used in industrial control systems. Response Surface Methodology (RSM) or commonly called the response surface method is a set of mathematical and statistical methods used in modeling and analysis, which aims to see the effect of several quantitative variables on a response variable and to optimize the response variable. The methodology of this research is to make a CSTR steady state reactor model into a dynamic model, then create a control model by determining the PI controller parameters using RSM, then tuning the $k c$ and ti parameters to the PI control by disturbing the setpoint. The results of the PI control system application obtained the fastest response time with a value of $k c=1.85, t i=1.15$ with a time of 0.5 minutes.

Keywords: continuous stirred tank reactor (CSTR), PI controller, set point

\section{Pendahuluan}

Reaktor adalah suatu alat proses tempat dimana terjadinya suatu reaksi berlangsung, baik itu reaksi kimia atau reaksi nuklir. Reaktor kimia adalah segala tempat terjadinya reaksi kimia, baik dalam ukuran kecil seperti tabung reaksi sampai ukuran yang besar seperti reaktor skala industri. Continuous Stirred Tank Reactor (CSTR) berupa suatu wadah yang umumnya berbentuk silinder dengan diameter tertentu, dimana reaktor dapat dalam kondisi terbuka (terjadi konveksi bebas antar reaktor dengan udara disekelilingnya). Dalam merancang pengendali untuk sebuah sistem reaktor, dibutuhkan beberapa pengendali yang ditempatkan pada reaktor CSTR salah satunya pengendali tekanan. Pengendalian terhadap tekanan ini merupakan keamanan utama dalam pabrik, terutama dalam kualitas produk yang dihasilkan. Kemudian tekanan yang tinggi dalam sistem tertutup dan kontinyu (terus-menerus) dapat menyebabkan terjadinya ledakan. Maka dari itu di jaga tekanan yang berada didalam sistem tertutup yaitu dengan mengendalikan tekanan didalam reaktor agar tetap aman.

Pada penelitian ini akan dikembangkan pengendalian sistem non linier multivariabel CSTR menggunakan aplikasi pengendali Proportional, Integrative, dan Derivative (PID) Controller. Parameter yang dikendalikan yaitu pressure. Proses pengontrolan di industri-industri pun banyak digunakan kendali 
konvensional seperti PID karena kesederhanaan struktur serta kemudahan dalam melakukan tuning parameter kontrolnya. Untuk menghasilkan produk yang maksimal, maka diberikan sebuah kondisi operasi reaktor yang harus dipenuhi misalnya laju alir, suhu, tekanan, dan level. Pengendalian tekanan yang di lakukan bertujuan untuk menjaga reaksi agar tetap berjalan sempurna didalam reaktor, dengan mengatur tekanan agar tetap berada dalam kondisi yang aman. Pada pabrik asetaldehida, suhu dan tekanan didalam reaktor sangat berpengaruh terhadap pembuatan asetaldehida, memerlukan banyak alat untuk memisahkan dan reaktan sehingga pabrik akan rugi. Reaksi hidrasi asetilena untuk pembuatan asetaldehida ini bersifat eksotermis. Sehingga perlu dilakukan pengendalian tekanan menggunakan kontrol PID agar tekanan didalam reaktor dapat dipertahankan sesuai dengan kondisi operasi reaktor yang ditetapkan.

\section{Teori}

Reaktor tangki pengaduk kontinyu (CSTR) adalah bejana dimana reaktan ditambahkan dan produk dikeluarkan sementara isi di dalam bejana diaduk dengan kuat dengan agitasi internal atau secara internal (atau eksternal) merecycle isinya. CSTR dapat digunakan secara seri atau paralel. Pendekatan untuk menggunakan CSTR secara seri adalah memiliki tangki silinder besar dengan pembagian: umpan memasuki bejana pertama dan dari atas (atau dari bawah) mengalir ke bejana berikutnya, dan seterusnya. Komposisi dijaga semaksimal mungkin di masing-masing bejana. Namun, gradien konsentrasi bergerak dengan cepat dari satu CSTR ke yang berikutnya. Bila reaktan memiliki kelarutan terbatas (miscibility) dan perbedaan densitas, reaktor vertikal bertahap (vertical stage reactor) maka operasi harus balik dapat digunakan. Sebagai alternative, setiap CSTR dalam rangkaian atau konfigurasi paralel bisa menjadi bejana independen (Pereira and Leib, 2008).

PID adalah akronim untuk "proportional, integral, dan turunan". Kontroler PID adalah sebuah pengontrol yang menyertakan elemen dengan tiga fungsi 
tersebut. Dalam literatur tentang PID pengontrol akronim juga digunakan pada level elemen: disebut dengan "elemen P", elemen integral sebagai "I elemen", dan turunannya elemen sebagai "D elemen". Kontroler PID pertama kali ditempatkan dipasar pada tahun 1939 dan tetap menjadi pengontrol yang paling banyak digunakan dalam control proses hingga saat ini. Sebuah investigasi yang dilakukan pada tahun 1989 di jepang menunjukkan bahwa lebih dari 90\% dari pengendali yang digunakan dalam industri proses adalah pengendali PID dan versi lanjutan dari kontroler PID (Araki, 2018).

Kontroler PID (Proportional Integral Derivative Controller), merupakan kontroler mekanisme umpan balik yang biasanya dipakai pada sistem kontrol industri. Sebuah kontroler PID secara kontinyu menghitung nilai kesalahan sebagai beda antara setpoint yang diinginkan dan variabel proses terukur (Tim Wescott FLIR System, 2000). Setiap kekurangan dan kelebihan dan masing-masing kontroler P, I dan D dapat saling menutupi dengan menggabungkan ketiganya secara paralel menjadi kontroler proporsional plus Integral plus differensial (kontroler PID). EIemen-elemen kontroler P, I dan D masing-masing secara keseluruhan bertujuan untuk mempercepat reaksi sebuah system menghasilkan offset dan menghasilkan perubahan awal yang besar (Gunterus, 1997). Pengendali PID menghasilkan output yang tergantung pada magnitude, Iamanya dan Iaju perubahan dari sistem sinyal error (Petruzella, 1996). Karakteristik kontroler PID sangat dipengaruhi oleh konstribusi besar dan ketiga parameter $\mathrm{P}$, I, dan $\mathrm{D}$. Penyetelan konstanta $\mathrm{K}_{\mathrm{c}}, \mathrm{T}_{\mathrm{i}}$, dan $\mathrm{T}_{\mathrm{d}}$ akan mengakibatkan penonjolan sifat dari masing-masing elemen. Satu atau dua dan ketiga konstanta tersebut akan memberikan konstribusi pengaruh pada respon system secara keseluruhan (Pieter and Wiria, 2011).

\section{Metode Penelitian}

Penelitian ini dilaksanakan di Laboratorium Komputasi Jurusan Teknik Kimia, Fakultas Teknik Universitas Malikussaleh (UNIMAL). Adapun tahapantahapan yang perlu dilalukan di dalam penelitian ini adalah: 


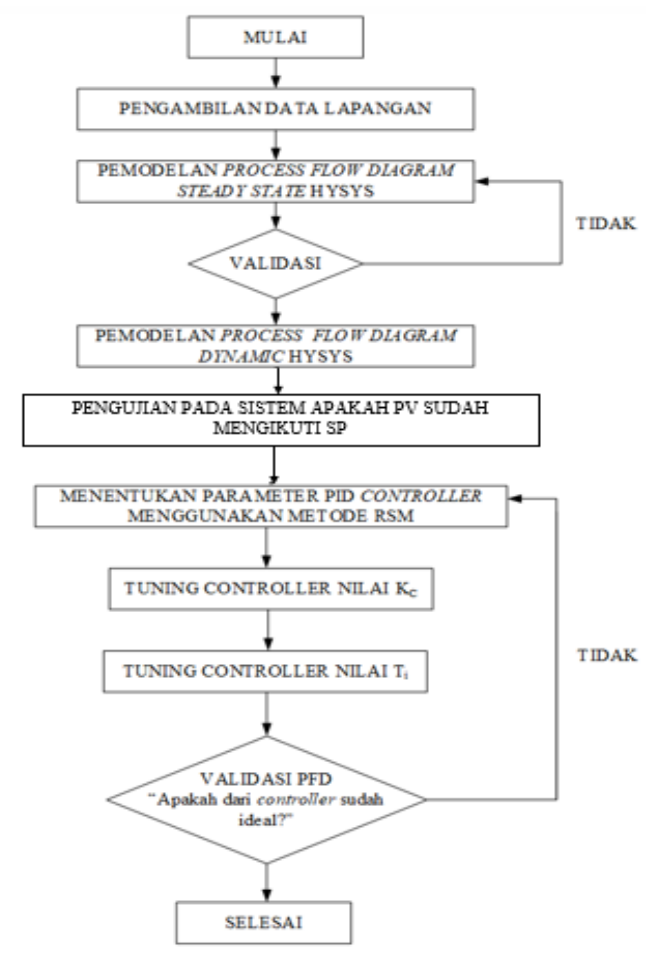

Gambar 1. Bagan Langkah Penelitian

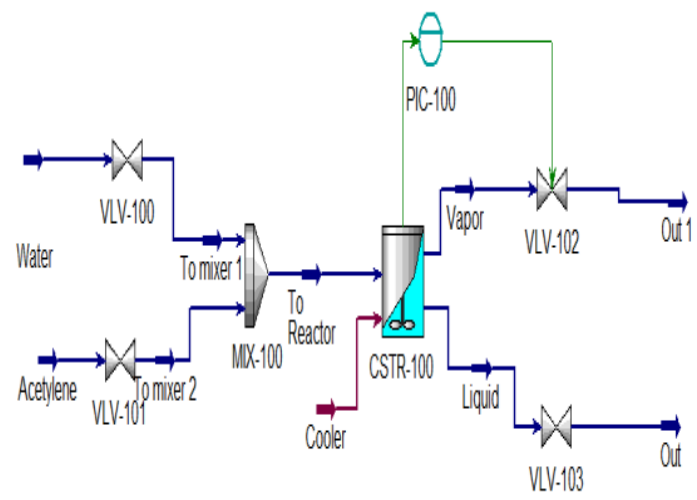

Gambar 2. Steady State Continuous Stirred Tank Reactor

1. Membuat model steady state Continuous Stirred Tank Reactor

2. Mengubah model steady state menjadi model dynamic CSTR

3. Membuat model kontrol PI

4. Menentukan parameter PI controller menggunakan software Response Surface Methodology (RSM)

5. Melakukan tuning terhadap Nilai Kc dan Ti 


\section{Pembahasan}

Pengujian terhadap model kontrol PI dilakukan untuk mengetahui kinerja dari model controller PI dengan menggunakan metode Respon Surface Methodology (RSM). Pada rancangan percobaan awal di RSM mendapatkan jumlah run sebanyak 13. Penelitian yang dilakukan mendapatkan hasil rancangan percobaaan yang ditunjukkan pada Tabel 1. Dalam pengujian kontrol PI dilakukan gangguan pada grafik Setponit (SP). Adapun hasil pengujian tuning parameter yang didapat dari nilai Respon Surface Methodology (RSM) yang dilakukan di dalam penelitian ini dapat dilihat pada Tabel 1.

Penelitian ini dilakukan untuk mendapatkan respon terbaik kontrol PI dengan upaya merancang sistem pengendalian tekanan pada reaktor cstr dengan mentuning nilai parameter yang telah di tentukan dengan menyesuaikan nilai parameter Kc dan Ti agar didapat waktu respon minimum dengan menjaga tekanan sesuai dengan kondisi operasi reaktor menggunakan Respon Surface Methodogy (RSM). Respon Surface Methodology (RSM) digunakan untuk mendapatkan rentang nilai parameter tuning Kc dan Ti agar diperoleh waktu yang optimal dan bukaan valve yang sesuai dengan tipe aktuator yang ditentukan. Penentuan konstanta kc, ti adalah hal yang sangat diperhatikan dalam pengontrolan PI. Nilai-nilai konstanta tersebut sangat berpengaruh terhadap control PI untuk melihat sejauh mana kemampuan kontrol tersebut bekerja. Nilai konstanta yang tidak tepat dapat mengakibatkan control tidak bekerja dengan sempurna atau tidak sesuai dengan keinginan proses. Penelitian model control proporsional and Integral (PI) pada pabrik etilena diklorida dengan kondisi proses yang bersifat dinamik. Dalam pengujian ini dilihat respon model kontrol dengan memvariasikan nilai present value (PV). 
Tabel 1 Data Hasil Penelitian Menggunakan Software Design Expert 7.0.0.

\begin{tabular}{|c|c|c|c|}
\hline Standart & $\begin{array}{c}\text { Faktor } 1 \\
\text { A: Kc }\end{array}$ & $\begin{array}{c}\text { Faktor } 2 \\
\text { B: Ti } \\
\text { (Menit) }\end{array}$ & $\begin{array}{c}\text { Waktu } \\
\text { mencapai } \\
\text { setpoint } \\
\text { PV } \\
\text { (Menit) }\end{array}$ \\
\hline 1 & 1,50 & 2,00 & 0,94 \\
\hline 2 & 1,00 & 1,50 & 0,75 \\
\hline 3 & 1,50 & 1,50 & 1 \\
\hline 4 & 1,15 & 1,85 & 1,2 \\
\hline 5 & 1,85 & 1,85 & 0,9 \\
\hline 6 & 1,85 & 1,15 & 0,5 \\
\hline 7 & 1,50 & 1,50 & 1 \\
\hline 8 & 2,00 & 1,50 & 0,7 \\
\hline 9 & 1,50 & 1,50 & 1 \\
\hline 10 & 1,50 & 1,00 & 0,55 \\
\hline 11 & 1,50 & 1,50 & 1 \\
\hline 12 & 1,50 & 1,50 & 1 \\
\hline 13 & 1,15 & 1,15 & 0,83 \\
\hline \multicolumn{2}{|c|}{ Run } & $\mathrm{Ti}$ & Waktu (Menit) \\
\hline \multicolumn{2}{|c|}{$1(1,080$ atm $)$} & \multirow{4}{*}{1,15} & 0,5 \\
\hline \multicolumn{2}{|c|}{$2(1,070 \mathrm{~atm})$} & & 0,6 \\
\hline \multicolumn{2}{|c|}{$3(1,060 \mathrm{~atm})$} & & 0,55 \\
\hline \multicolumn{2}{|c|}{$4(1,050 \mathrm{~atm})$} & & 1 \\
\hline \multicolumn{2}{|c|}{ Rata-rata } & & 0,6625 \\
\hline
\end{tabular}

\section{Respon Surface Methodology Terhadap Waktu}

Hasil setting trial and error yang dihasilkan pada RSM diperlukan untuk melakukan optimasi pada respon kontroler system tersebut. Hasil dari penelitian ini kemudian di analisa menggunakan Design Expert. Table 2 berikut ini merupakan table Analisa varian (ANOVA) yang berfungsi untuk merespon waktu. 
Tabel 2 Analisa Varian (ANOVA) untuk Respon Waktu

\begin{tabular}{|c|c|c|c|c|c|c|}
\hline Source & $\begin{array}{c}\text { Sum Of } \\
\text { Squares }\end{array}$ & $d f$ & $\begin{array}{c}\text { Mean } \\
\text { Square }\end{array}$ & $\begin{array}{c}F \\
\text { Value }\end{array}$ & $\begin{array}{c}\text { P-Value } \\
\text { Prob } \gg \mathrm{F}\end{array}$ & Keterangan \\
\hline Model & 0,41 & 5 & 0,082 & 7,61 & 0,0095 & Significant \\
\hline A-Kc & 0,061 & 1 & 0,061 & 5,72 & 0,0480 & - \\
\hline B-Ti & 0,22 & 1 & 0,22 & 20,35 & 0,0028 & - \\
\hline AB & $2,250 \mathrm{E}-004$ & 1 & $2,250 \mathrm{E}-004$ & 0,021 & 0,8889 & - \\
\hline$A^{2}$ & 0,079 & 1 & 0,079 & 7,41 & 0,0297 & - \\
\hline$B^{2}$ & 0,065 & 1 & 0,065 & 6,09 & 0,0430 & - \\
\hline Residual & 0,075 & 7 & 0,011 & - & - & - \\
\hline Lack of Fit & 0,075 & 3 & 0,025 & - & - & - \\
\hline Pure Error & 0 & 4 & 0,00 & - & - & - \\
\hline Cor Total & 0,48 & 12 & - & - & - & - \\
\hline
\end{tabular}

Design Expert RSM 7.0.0.

Tabel 2 menunjukkan uji parameter, untuk memeriksa signifikan pada model. Dilihat dari $\mathrm{P}_{\text {value }}$ yaitu 0,0095 lebih kecil dari derajat signifikan $\alpha=5 \%$, hal ini menunjukkan bahwa variabel-variabel tersebut memiliki keterkaitan. Apabila nilai probabilitas > F lebih kecil dari 5\% maka akan menunjukkan model yang signifikan dan jika lebih dari 0,05, maka bentuk model tersebut tidak signifikan secara statistik. Model yang diperoleh dari erksperimen ini adalah:

$$
\mathrm{y}=-2,86175+2,22726 \times \mathrm{Kc}+2,70224 \times \mathrm{Ti}+0,060000 \times \mathrm{Kc} \times \mathrm{Ti}-
$$

$0,85500 \times \mathrm{Kc}^{2}-0,77500 \times \mathrm{Ti}^{2}$

Kemudian dilakukan pengujian residual untuk memeriksa kecocokan model. Analisa ini dapat dilihat pada Tabel 3 dan Gambar 2.

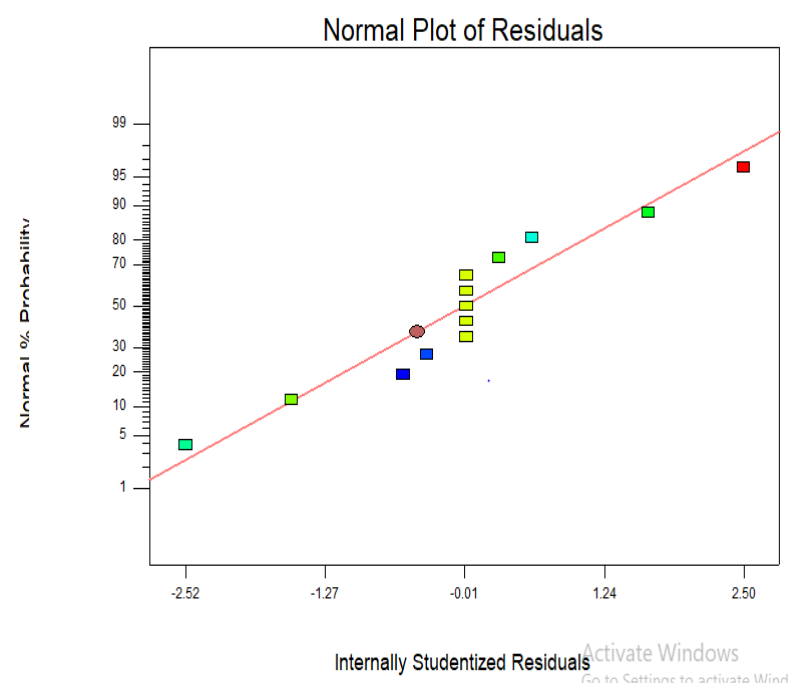


Tabel 3 Analisa R-Squared untuk Respon Waktu

\begin{tabular}{|l|c|}
\hline Std. Dev. & 0,10 \\
\hline Mean & 0,87 \\
\hline C.V. \% & 11,84 \\
\hline PRESS & 0,53 \\
\hline R-Squared & 0,8446 \\
\hline Adj R-Squared & 0,7336 \\
\hline
\end{tabular}

Tabel di atas menunjukkan R-squared, model dapat dikategorikan sebagai model yang sesuai apabila model tersebut memiliki koefisien korelasi $\mathrm{R}^{2}$ mendekati 1. Pada tabel diketahui $\mathrm{R}^{2}=0,8446$ yang menunjukkan bahwasanya model sudah sesuai dengan nilai variabel Kc dan Ti yang memberikan pengaruh terhadap respon kontrol. Grafik residual dapat dilihat pada gambar 2 untuk uji distribusi normal, dengan asumsi distribusi normal dilakukan dengan melihat plot probabilitasnya dan menunjukkan bahwa plot di atas mendekati garis lurus, sehingga dapat dikatakan bahwa residual berdistribusi normal. Nilai $\mathrm{R}^{2}$ terkoreksi (Adj $R^{2}$ ) mengkoreksi nilai $\mathrm{R}^{2}$ terhadap variabel $\mathrm{kc}$, ti, dan td tidak terlalu besar, maka nilai $\mathrm{R}^{2}$ terkoreksi akan lebih kecil dari $\mathrm{R}^{2}$ sebesar 0,7336 . Nilai $\mathrm{R}^{2}$ prediksi (pred. $\mathrm{R}^{2}$ ) cukup bersesuaian dengan $\mathrm{R}^{2}$ terkoreksi. Hasil anova pada Response Surface Methodologi tersebut di plotkan menjadi grafik 3D Surface dilihat pada gambar 3 yaitu model grafik $3 D$ surface untuk variabel time.
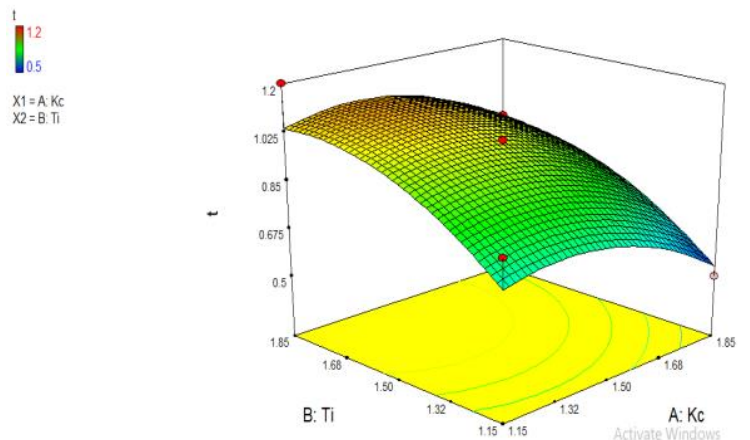

Gambar 3 Model Grafik 3D Surface Untuk Variabel Time

Gambar tersebut menunjukkan titik optimum time (y) dari interaksi Ti (xi) dan $\mathrm{Kc}\left(\mathrm{x}_{2}\right)$. Titik optimum dari interaksi tersebut di dapat pada $\mathrm{Kc}=1,15$ dan $\mathrm{Ti}=$ 1,85 maka time (menit) yang diperoleh adalah 1 menit dan titik minimum yang 
diperoleh $\mathrm{Kc}=1,85$ dan $\mathrm{Ti}=1,15$ maka time (menit) yang diperoleh adalah 0,5 menit.

\section{Penentuan Kondisi Optimum}

Nilai parameter untuk masing-masing variabel bebas dan variabel terikat ditunjukkan pada Tabel 4.

Tabel 4 Hasil Optimasi Nilai Kc dan Ti terbaik

\begin{tabular}{|c|c|c|c|c|c|c|}
\hline \multirow{2}{*}{ Nama } & \multirow{2}{*}{ Pencapaian } & Terendah & Tertinggi & Terendah & Tertinggi & Penting \\
\cline { 3 - 7 } & Batas & Batas & Berat & Berat & \\
\hline A: Kc & $\begin{array}{c}\text { Didalam } \\
\text { range }\end{array}$ & 1,14645 & 1,85355 & 1 & 1 & 3 \\
\hline B:Ti & $\begin{array}{c}\text { Didalam } \\
\text { range }\end{array}$ & 1,14645 & 1,85355 & 1 & 1 & 3 \\
\hline Waktu & Minimum & 0,5 & 1 & 1 & 1 & 3 \\
\hline
\end{tabular}

Design Expert RSM 7.0.0.

Tabel Response Surface Methodology tersebut memberikan nilai optimasi yang terlihat pada Tabel 5 dibawah ini.

\section{Tabel 5 Titik Optimum}

\begin{tabular}{|c|c|c|c|c|}
\hline $\mathrm{Kc}$ & $\mathrm{Ti}$ & Time & Desirabilitas & $\cdot$ \\
\hline 1,85 & 1,15 & 0,335972 & 0,449 & Dipilih \\
\hline
\end{tabular}

Design Expert RSM 7.0.0.

Dari hasil optimasi tersebut dapat diketahui bahwa kombinasi pressure variabel bebas yang mampu memberikan nilai respon optimum adalah pada kondisi $\mathrm{Kc}=1,85$ dan $\mathrm{Ti}=1,15$ dengan waktu 0,5 menit. Waktu respon terlama pada $\mathrm{Kc}=1,15, \mathrm{Ti}=1,85$, Time $=1$ menit. Berdasarkan faktor karakteristik dari kontrol PI, jika nilai Kc kecil pengontrol proporsional hanya mampu melakukan koreksi kesalahan yang kecil sehingga akan menghasilkan respon sistem yang lambat, jika nilai Kc diperbesar sehingga mencapai harga yang berlebihan, akan mengakibatkan sistem bekerja tidak stabil atau respon sistem akan berosilasi. Namun apabila pemilihan nilai Ti yang sangat tinggi justru dapat menyebabkan output berosilasi, jika pemilihan Ti yang tidak tepat juga dapat menyebabkan 
respon transien yang tinggi sehingga dapat menyebabkan ketidakstabilan sistem. Validasi hasil prediksi terhadap data hasil eksperimen dapat dilihat pada Tabel 6.

\section{Tabel 6 Validasi Hasil Prediksi Model Terhadap Data Eksperimen}

\begin{tabular}{|c|c|c|c|c|c|}
\hline Run & $\mathrm{Kc}$ & $\mathrm{Ti}$ & $\begin{array}{c}\text { Waktu mencapai SP } \\
\text { (Eksperimen (menit)) }\end{array}$ & $\begin{array}{c}\text { Waktu mencapai SP } \\
\text { (Prediksi (menit)) }\end{array}$ & $\begin{array}{c}\text { Persen Kesalahan } \\
(\%)\end{array}$ \\
\hline 1 & 1,50 & 2,00 & 0,83 & 0,73 & 0,10 \\
\hline 2 & 1,00 & 1,50 & 0,5 & 0,54 & 0,036 \\
\hline 3 & 1,50 & 1,50 & 1,20 & 1,04 & 0,16 \\
\hline 4 & 1,15 & 1,85 & 0,90 & 0,88 & 0,019 \\
\hline 5 & 1,85 & 1,85 & 0,75 & 0,91 & 0,16 \\
\hline 6 & 1,85 & 1,15 & 0,70 & 0,66 & 0,038 \\
\hline 7 & 1,50 & 1,50 & 0,55 & 0,57 & 0,023 \\
\hline 8 & 2,00 & 1,50 & 0,94 & 1,04 & 0,100 \\
\hline 9 & 1,50 & 1,50 & 1,00 & 1,00 & 0 \\
\hline 10 & 1,50 & 1,00 & 1,00 & 1,00 & 0 \\
\hline 11 & 1,50 & 1,50 & 1,00 & 1,00 & 0 \\
\hline 12 & 1,50 & 1,50 & 1,00 & 1,00 & 0 \\
\hline 13 & 1,15 & 1,15 & 1,00 & 1,00 & 0 \\
\hline
\end{tabular}

Design Expert RSM 7.0.0.

Dari Tabel 6 di atas menjelaskan perbandingan antara data dari hasil eksperimen dan data dari hasil prediksi RSM. Persen kesalahan didapat dari pengurangan data eksperimen dan data prediksi dibagi dengan data eksperimen. Error yang didapat di bawah $1 \%$ yang artinya hasil antara prediksi dan eksperimen tidak terlalu besar perbedaannya. Pada run 9 sampai run 13 didapat error 0 dikarenakan antara waktu mencapai setpoint eksperimen dengan waktu mencapai setpoint prediksi sama, sehingga tidak ada terjadinya penyimpangan maka didapatlah error 0 (Dian dkk, 2011).

\section{Uji Gangguan Kontrol PI dengan Tuning Parameter Kc dan Ti Optimum}

Pada pengontrolan PI diperlukan pengujian yang bertujuan untuk mengetahui parameter nilai kc dan ti itu berjalan dengan baik terhadap kontrol yang digunakan. Oleh sebab itu, diberikan gangguan pada set point untuk mengetahui apakah nilai present value (PV) berhasil mengejar nilai set point 
apabila diberikan gangguan dengan cara mentuning nilai kc dan ti. Uji gangguan awal kontrol PI pada tekanan Reactor CSTR sebelum dilakukan tuning parameter nilai kc dan ti, dapat dilihat pada gambar 4.

\section{Gambar 4 Grafik Kontrol PI sebelum dilakukan tuning nilai kc dan ti.}

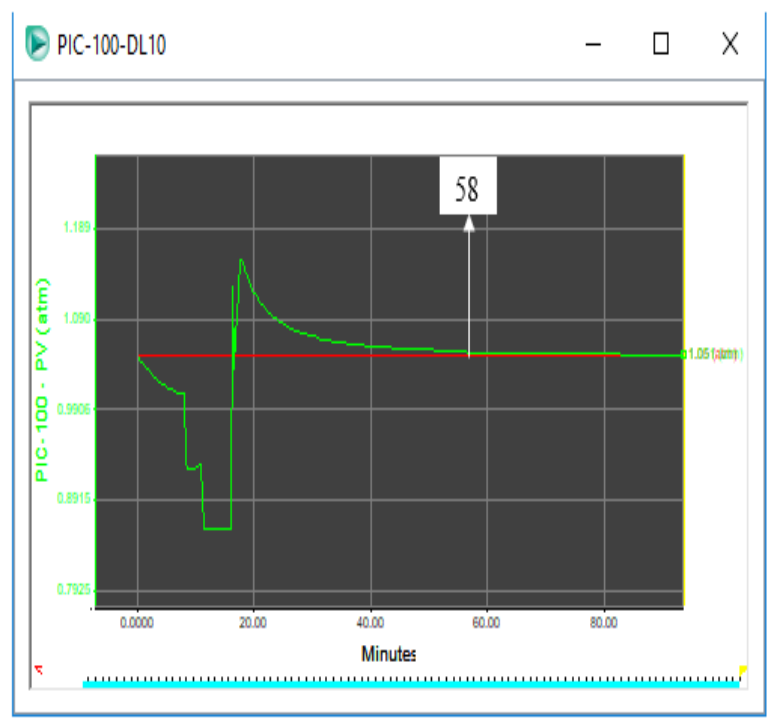

Dapat dilihat dari gambar 4 bahwa respon control untuk mencapai setpoint dibutuhkan waktu yang cukup lama. Adapun waktu yang dibutuhkan untuk mencapai setpoint sebesar 58 menit. Hal ini menandakan bahwa perlu dilakukan tuning parameter $\mathrm{kc}$ dan ti guna untuk mempercepat respon. Karena apabila respon kontrol didalam suatu sistem lama, maka akan mempengaruhi kualitas produk yang dihasilkan. Kemudian dilakukanlah tuning terhadap control tekanan agar respon berjalan sesuai dengan yang diinginkan. Berikut ini adalah hasil dari pengujian tuning parameter $\mathrm{Kc}=1,85 \mathrm{Ti}=1,15$ dalam bentuk grafik model PI pada Gambar 5. 


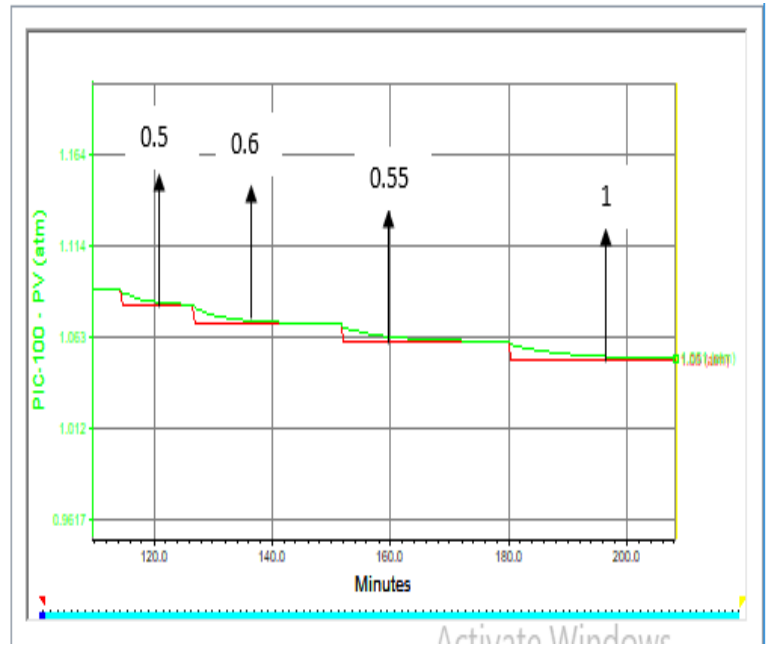

\section{Gambar 5 Grafik hasil pengujian model $\mathrm{PI}$, nilai $\mathrm{Kc}=1,85$ dan $\mathrm{Ti}=\mathbf{1 , 1 5}$ (Keterangangambar: garis pressure control set point (SP)).}

Gambar 5 menunjukkan hasil pengaruh nilai Kc dan Ti untuk waktu yang dicapai oleh kontroler PI. Nilai $\mathrm{Kc}=1,85$ dan $\mathrm{Ti}=1,15$ sangat mempengaruhi nilai keluaran controller. Nilai Kc berfungsi sebagai penambah kestabilan pada system, Jika nilai kc dinaikkan, respon/ tanggapan sistem akan semakin cepat mencapai keadaan maksimal (mengurangi rise time). Namun jika nilai kc diperbesar sehingga mencapai harga yang berlebihan, akan mengakibatkan sistem bekerja tidak stabil atau respon akan berosilasi. Dapat dilihat dalam hal ini perbedaan sebelum dan sesudah dilakukan tuning parameter nilai kc dan ti. Dari pengujian nilai $\mathrm{kc}=1,85$ dan nilai $\mathrm{t}=1,15$ di dapat grafik respon yang cukup baik, dibuktikan dari proses variabel yang selalu mengikuti saat set point di ubah-ubah. Hasil respon kontroler di atas juga mampu mengurangi system bergejolak atau berosilasi.

Dalam hal ini, waktu respon yang didapat sebelum pengujian tuning parameter nilai kc dan ti, waktu yang dibutuhkan untuk mencapai set point 1.090 atm sebesar 58 menit seperti yang terlihat pada gambar 4. Kemudian diganggu dengan menurunkan nilai setpoint sebesar 1,080 atm dan present value mengikuti dengan memerlukan waktu respon sebesar 0,5 menit, diturunkan kembali nilai set point untuk mengganggu kendali kontrol sebesar 1.070 atm didapatkan waktu respon sebesar 0,6 menit, kemudian di turunkan kembali nilai setpoint menjadi 
1,060 atm mendapatkan waktu respon sebesar 0,55 menit, dan terakhir diganggu nilai setpoint menjadi 1,050 atm mendapatkan waktu respon sebesar 1 menit. Dalam hukum teori controller, pada kasus ini controller sudah dikatagorikan berhasil dikarenakan waktu respon mencapai set point cukup cepat.

Pada pengujian tuning parameter optimum yang didapat dari hasil Respon Surface Methodology (RSM) tuning parameter $\mathrm{Kc}=1,85, \mathrm{Ti}=1,15$, dengan waktu rata-rata dalam menghadapi gangguan setpoint (SP) sebesar 0,6625 menit dan tuning parameter tersebut juga merupakan rekomendasi tuning untuk pressure control (Levine, Technology, Dissinger, Management, \& Technology, 2013). Pada tuning tersebut waktu yang diperlukan pada respon cepat dan itu dibutuhkan untuk pressure control yang dipasangkan pada Reaktor CSTR. Sehingga kelebihan dan kekurangan untuk Reaktor CSTR dapat ditangani dengan cepat dan kerugian yang disebabkan oleh gangguan dapat diperkecil. Berikut ini adalah tabel pengaruh kontrol tekanan terhadap produk CSTR seperti yang terdapat pada Tabel 7.

Tabel 7 Pengaruh Kontrol Tekanan Terhadap Produk dengan gangguan

\begin{tabular}{|c|c|c|c|c|c|c|c|c|c|}
\hline \multicolumn{10}{|c|}{ Bomon's: } \\
\hline Konowent & Water & tetlens & To Reactor & Vroot & Liguid & Out: & ToMire? & To mine ! & ont! \\
\hline $\mathrm{H} 20$ & 0.796 & 1 & 0.32 & 0. & 0.1 & 0. & 0 & $0779 \%$ & 0.05 \\
\hline Itand & 0 & 1 & 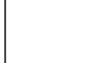 & & 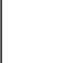 & 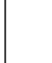 & 0 & 1 & 0 \\
\hline Astatdenidg & 0.2404 & & 067 & 0 & 0.9 & $0 !$ & 1 & 0.240. & 0.95 \\
\hline
\end{tabular}

tekanan $(1,080,1,070,1,060$, dan 1,050$)$

Dari Tabel 7 di atas menunjukkan satu keluaran produk asetaldehida yang dihasilkan dari reaktor CSTR tidak berpengaruh signifikan terhadap produk yang dihasilkan yaitu dengan konversi 95\% dengan gangguan tekanan sebesar 1,080, 1,070, 1,060, dan 1,050. 


\section{Simpulan}

Berdasarkan hasil yang telah diperoleh pada penelitian ini dapat disimpulkan:

1. Pada pengujian menggunakan Respon Surface Methodology (RSM) didapatkan hasil tuning parameter optimum sebesar Kc 1,85 Ti 1,15.

2. Waktu tercepat dalam merespon gangguan yaitu dengan nilai tuning parameter optimum $\mathrm{Kc}=1,85 \mathrm{Ti}=1,15$ dengan rata-rata waktu yang dibutuhkan untuk menghadapi gangguan sebesar 0,6625 menit.

3. Kontrol tekanan tidak berpengaruh signifikan terhadap produk.

4. Model $\mathrm{P}_{\text {value }}$ pada respon waktu diperoleh nilai sebesar 0,0095 lebih kecil dari derajat signifikan $\alpha=5 \%$ yang menunjukkan adanya keterkaitan terhadap respon.

\section{Daftar Pustaka}

Aboelela, Magdy A. S, Rania H. M. H dan Hassen T. D. 2012. Design And Implementation of A PID Controller For A Continuous Stirred Tank Reactor (CSTR) System Using Particle Swarm Algorithms. Egypt: Cairo University, Faculty of Engineering, Giza.

Araki Mituhiko. Control System, Robotics, And Automation-Vol. Ii-Pid Control. Aspen Technologi, Inc. 2004. Dynamic Modeling. Cambridge, USA.

Brogan,W. L. 1985. Modern Control Theory, Prentice-Hall, Inc. New Yersey.

Cheng. 2006. Netwoked and Distributed Predictive Control, Advanced Industrial Control. London : Springer-verlag.

Coulson, J.M. and Richardson, J.F., 1983, "Chemical Engineering”, Pergamon Press, Oxford.

Dian Anggraeni, Ria Faulina and Shofi Andari (2011) Response Surface Methodology (RSM) Dan Aplikasinya, Surabaya.

Dissinger, G. 2012. Getting Started with Aspen HYSYS Dynamics Solving safety and operability challenges. Aspen Technology.

Didik Wahjudi, Lely Tjandranitia Dewi and Gan Shu San (1999) 'Optimasi Kualitas Warna Minyak Goreng Dengan Response Surface Methodolgy', Jurnal Teknik Industri, 1 (1), pp. 18-29. Available at: http://puslit2. Petra. 
Ac. id./ejournal/index.php/ind/article/view/15978.

Fogler, H. Scoot. 2006. Elements of Che mical Reaction Engineering. $4^{\text {th }}$ ed. London: R. K. Sinnot.

FLIR System, Tim Wescott. 2000. Paper: PID Without A PhD. India: EE Times India.

Frank D Petruzella. 1996. ElektronikaIndustri. Yogyakarta: Andi.

Gunterus, Frans, 1997, Falsafah Dasar Sistem Pengendalian Proses, PT. Elex Media Komputindo, Jakarta.

Julie, L. G. D. (2013) 'Jump Start : Aspen HYSYS Dynamics V8’.

Jonsson, M. Acetaldehyde-An Important Platform Chemical. SEKAB. Diakses pada 12 Januari $2018 \mathrm{http} / / /$ www. Sekab.com/chemistry/acetaldehyde/.

Kirk and Othmer. 1960. Encyclopedia of Chemical Technology. Volume 1. Fourth Edition. John Wiley and Sons Inc: New York.

Lewis, 1985 on the dynamic behavior of continuous stirred tank. Chemical Engineering Sciene, 29, 957-985.

Levenspiel, O.1999. Chemical Reaction Engineering, Ed. $3^{\text {rd }}$. John Wiley and Sons: New York.

Liptak, Bela G. 2006. Process Control And Optimization. Boca Raton: CRC Press Taylor And Francis Group.

Luyben, W.L. 2007 Chemical Reactor Design and Control. Canada: Lehigh University.

Mursyitah, Dian, dkk. "Control of Continuous Strirred Tank Reactor (CSTR) using Decouple Sliding Mode Controller " SENAKI, 2013.

Mukhaitir, A. S., Setiawan, I. and Sumardi (2010) 'Aplikasi Kendali Pid Menggunakan Skema Gain Scheduling Untuk Pengendalian Suhu Cairan Pada Plant Electric Water Heater', Transmisi, 12(1), pp. 27-32.

Ogata Katsuhiko. 1996. Teknik Kontrol Automatic. Diterjemahkan oleh Edi Laksono. Jakarta: Erlangga.

P. Pieter, D. Wira. (2011) Sistem Pengendalian PID Yang Diaplikasikan Pada Pengendalian Steam Turbin Dengan Single Variable Input dan Single Output. Staf Pengajar Jurusan Teknik Elektro Fakultas Teknik Universitas Tadulako, Palu.

Pereira, C. J. and Leib, T. M. (2008) Section 19. Reactors, Perry's Chemical Engineers' Handbook. Doi: 10.1036/0071511423. 
Pratomo, A. V. (2012) 'Perancangan Pengendali PID Pada Pressure Process RIG (38-714) Berbasis Mikrokontroller AVR ATMega8535' Jurnal Teknik Elektro: Universitas Pancasila.

Rahmat, M. F. (2011) 'Temperature Control of a Continuous Stirred Tank Reactor By Means of Two Different', International Journal on Smart Sensing and Intelligent Systems, 4(2), pp. 244-267.

Rama Oktavian, Dwi Saptati. 2017. Aplikasi Spreadsheet untuk Perhitungan Teknik Kimia. Malang: UBPress.

Ritonga, Y. (2010) 'Pengendalian Proses Kimia', Proses Pengendalian Kimia, II (1), pp. 1-21.

Rosadi, H. Y. (2000) 'Pemodelan Continuous Stirred Tank Reactor'.

R. Wang, C. Tan, J. Xu dkk. (2017) 'Pressure Control for a Hydraulic Cylinder Based on a Self-tuning PID Controller Optimized by a Hybrid Optimization Algorithm'. Doi: 10.3390/a10010019.

Saputra, Anggi. (2017) "Pengendalian Level dan Konsentrasi Pada Continuous Stirred Tank Reactor (CSTR) Menggunakan Sliding Mode Control Dengan Permukaan Luncur Proportional Derivative".

Setiawan, I. 2008. Kontrol PID Untuk Proses Industri. Penerbit: Elex Media Komputindo, Bandung.

Sellers, David. (2007) “An Overview of Proportional PLUS Integral Plus Derivatif Control and Suggestions for Its Succesfull Application and Implementation".

Smith, J.M., 1981, “Chemical Engineering Kinetics”, 3 ed., Mc. Graw Hill Book Company, Inc ., New York.

Sinnott, R. and Towler, G. (2013) Chemical Engineering Design-Principles, Practice and Economics of Plant and Process Design Second Edition, Chemical Engineering Design.Doi:10.1016/B978-0-08-096659-5.00022-5.

Thomas, C. E. (2015) Process Technology Equipment and Systems Fourth Edition. United States of America.

Vardeman, S. B. and Marcus Jobe J. (1998) Statistical Quality Assurance Methods for Engineers. Illustrate. Wiley, 1999.

V. Agarwal, A. Deo, N. Kumar dkk. (2015) 'Temperature Control of CSTR using PID Controller', Internasional Journal of of Engineering And Computer Science. 
Irma Yuliana Damanik, dkk / Jurnal Teknologi Kimia Unimal 8 : 2 (November 2019) 97 - 114

W., R., Missen, C.A. and Saville, M. and B. A. (1999) Ronald W. Missen Charles A. Mims Bradley. A. Saville, New York.

Winterbottom, J. M and Michael, King. 1999. Reactor Design for Chemical Engineering. Florida: CRC Press.

www.gmdu.net . Global trade Harsh\&Vardhan Impex Pvt. Ltd. Diakses pada 03 Januari 2018. Hhtps://www.gmdu.net/corp-293085.html. 